qua, có lạm dụng rượu bia, có ăn mặn, không có hoạt động thể lực liên quan với kiến thức về phòng chống tăng huyết áp. Tương tự như kết quả nghiên cứu của tác giả Thái Thanh Trúc [7].

\section{KẾT LUÂN}

Tỷ lê đồng bào Chăm có thực hành chung đúng về phòng chống tăng huyểt áp còn thấp. Để nâng cao tỷ lệ kiến thức đúng về phòng chống bênh tăng huyết áp cho đồng bào Chăm cần chú trọng các biện pháp truyền thông giáo dục sức khỏe bằng ngôn ngữ Chăm.

\section{TÀI LIÊU THAM KHẢO}

1. Nguyễn Thanh Bình (2017), Thực trạng bênh tăng huyết áp ở người Khmer tỉnh Trà Vinh và hiêu quả một số biện pháp cañn thiệp, Luận án Tiến sĩ Y hoc, Viền Vê sinh Dich tể Trung ương, tr.70-115.

2. Chu Thị Thu Hà (2014), "Nghiên cứu tỷ lệ hiểu biết đúng của người dân về bệnh tăng huyết áp". Tap chí Y hoc thực hành, Số 1 (903), tr.9-11.

3. Hoàng Đức Hạnh, Chu Thị Thu Hà (2015), "Kiến thức của người dân về các yếu tố nguy cơ của bệnh tăng huyết áp tại ba xã/phường Hà Nội năm 2013". Tạp chí Y học dự phòng, Tập 25, Số 6̆, $\operatorname{tr} 410-416$.

4. Đố Thái Hòa, Nguyễn Thị Thùy Dương, Dương
Thị Hồng, Phan Trọng Lân (2016), "Thực trạng kiến thức và một số yếu tố liên quan đến tình trạng tăng huyết áp ở nhóm tuổi trung niên (40-59) tại huyện Đông Sơn, tỉnh Thanh Hóa, năm 2013". Tạp chí Ý học Dự phòng, Tập 26, Số 4, tr.30-38.

5. Nguyến Tuấn Khanhi, Nguyến Minh Đức, Ta Vắn Trâm (2012), "Kiến thức, thực hành về phòng ngừa, điều trị tăng huyết áp ở người cao tuổi tai thành phố Mỹ Tho năm 2011". Tạp chí Y học thành phố Hồ Chì Minh, Tập 16, Số 4, tr.230-235.

6. Trân Văn Tân, Trương Quang Đạt (2015), "Kiến thức và thức hành vể phòng chống tăng huyết áp của người dân ở các xã đảo của thành phố Quy Nhơn". Tạp chí Y học Dự phòng, Tập 25, Số 9 , tr.128-133.

7. Thái Thanh Trúc, Nguyễn Thị Mỹ Dung, Huỳnh Hồ Ngọc Quỳnh (2019), "Kiến thức, thá độ và thức hành vê tăng huyết áp ở bệnh nhân tăng huyết áp đến khám và điều trị tại bệnh viện quân 2, thành phố Hồ Chí Minh". Tạp chí Y học thành phố Hồ Chí Minh, 23 (5), tr.224-232.

8. Nguyễn Lân Việt (2016), Kết quả mới nhất điều tra tăng huyết áp toàn quốc năm 2015 - 2016, Hội tim mạch học Việt Nam

9. ChimberengwaI P.T., Naidoo M., et al. (2019), "Knowledge, attitudes and practices related to hypertension among residents of a disadvantaged rural community in southern Zimbabwe". PLoS One, 14 (6), pp.1-16.

\title{
NGHIÊN CỨU ĐĂC ĐIỂM LÂM SÀNG CỦA RỐI LOẠN LO ÂU LAN TỎA
}

\section{TÓM TẮT.}

Mục tiêu: nghiên cứu đặc điểm lâm sàng rối loạn lo âu lian toả bằng thang điếm HAM-A. Đối tượng và phương pháp nghiên cứu: 62 bệnh nhân rối loạn lo âu lan toả được điều trị nội trú tại Khoa Tâm thần, Bệnh viện Quân y 103. Kết quả: beệnh nhân tái phát lần hai chiếm tỷ lệ cao $59,68 \%$ và có tới $56,46 \%$ bệnh nhân khám không đúng chuyên nhành. Các triệu chứng khởi phát thường găp của bênh nhân là triệu chứng hồi hộp $(95,16 \%)$ và thời gian mang bệnh là $15,38 \pm 9,85$ tháng. Phẩn lớn chủ đề lo âu về bệnh tật $(82,26 \%)$, thời gian tồn tại của triệu chứng trung bình $19,35 \pm 11,26$ phút. Ngoài ra triệu chứng tâm thần thường gặp nhất là triệu chứng chóng mặt $(83,87 \%)$ và điểm HAM-A cho nặng chiếm tỉ lệ cao nhất với $53,22 \%$. Kết luận: Lâm sàng rối loạn lo âu lan toả rất đa dang và phơng phú.

Tư khóa: Rối loạn lo âu lan tỏa, thang điểm HAM-A.

\section{SUMMARY}

${ }^{1}$ Bệnh viện Quân y 103

Chịu trách nhiệm chính: Đinh Việt Hùng

Email: bshunga6@gmail.com

Ngày nhận bài: 20.01.2021

Ngày phản biện khoa học: 22.3.2021

Ngày duyệt bài: 30.3.2021

\section{Đinh Việt Hùng ${ }^{1}$, Nguyễn Duy Đông ${ }^{1}$} STUDY ON CLINCAL CHARACTERISTIC OF GENERALIZED ANXIETY DISORDER

Objective: Using the HAM-A scale to study the clinical characteristics of generalized anxiety disorder. Subjects and research methods: 62 inpatient with generalized anxiety disorder received treatment at the Department of Psychiatry, Military 103 Hospital. Results: Second relapse patients accounted for a high rate of $59.68 \%$ and $56.46 \%$ of patients did not exam right major. The most common onset symptoms of patients were palpitations (95.16\%) and duration of illness was $15.38 \pm 9.85$ months. Most worry about illness $(82.26 \%)$, duration of existence symptoms averaged $19.35 \pm 11.26$ minutes. In addition, the most common psychiatric symptoms were dizziness $(83.87 \%)$ and HAM-A scores for severe were the highest with 53.22\%. Conclusion: Clinical characteristics of generalized anxiety disorder is very diverse and plentiful

Keywords: Generalized anxiety disorder, HAM-A scale

\section{I. ĐĂT VẤN ĐỀ}

Rối loạn lo âu lan toả được đặc trưng bởi các lo lắng quá mức về một sự kiện hoặc các hoạt động, diền ra hầu như hàng ngày trong suốt một thời gian ít nhất 6 tháng. Các triệu chứng của rối 
loan lo âu lan toả đa dang và phong phú bao gồm: các triệu chứng kích thích thần kinh thực vật, các triệu chứng vùng ngực, bụng, các triệu chứng liên quan đến trang thái tâm thần và một số triệu chứng khác. Bệnh nhân không thể kiểm soát được các lo lắng này, giảm khả năng lao động, sinh hoạt và các chức năng quan trọng khác. Sự đa dạng, phong phú của các triệu chứng gây không ít khó khăn trong nhận biết và xác định chẩn đoán. Các nghiên cứu trên thễ giới chỉ ra rằng tỷ lệ bệnh nhân rối loạn lo âu lan tỏa rất khác nhau trong đó lo âu: $13,3 \% ; 34,7 \%$ với các triệu chứng đau và $32,5 \%$ với các rối loạn giấc ngủ [1]. Do vậy, xác định chính xác đặc điểm lâm sàng rối loạn lo âu lan toả là cần thiết giúp chẩn đoán đúng và điều trị hiêu quả. Chính vì vậy chúng tôi tiến hành đề tài "Nghiên cúu đặc điểm lâm sàng của rối loạn lo âu lan toả".

II. ĐốI TƯợNG VÀ PHƯƠNG PHÁP NGHIÊN CứU

2.1. Đối tượng nghiên cứu. Sáu hai bệnh nhân được chẩn đoán là rối loạn lo âu lan tỏa (F41.1) theo ICD-10 (1992), được điều trị nội trú tại khoa Tâm thần, Bệnh viện Quân y 103 từ tháng 4/2016 đến tháng 8/2020.

2.2. Phương pháp nghiên cứu. Sử dụng phương pháp nghiên cứu hồi cứu mô tả cắt ngang, phân tích đánh giá từng trường hợp cụ thể. Các triệu chứng lâm sàng được đánh giá trong ngày đầu bệnh nhân vào viện, việc đánh giá được tiến hành độc lập bởi hai bác sĩ chuyên nghành tâm thần.

2.3. Phân tích số liệu. Phân tích số liệu được tiến hành trên phần mềm phân tích số liệu SPSS 20.0. Sự khác biệt có ý nghĩa thống kê được xác định cho các kiểm định với mức $\mathrm{p}<0,05$.

\section{KẾT QUẢ NGHIÊN CỨU VÀ BÀN LUÂ̂N}

3.1. Đặc điểm chung nhóm nghiên cứu

Bảng 3.1. Tuổi của nhóm bệnh nhân nghiên cứu

\begin{tabular}{|c|c|c|}
\hline Nhóm tuối & $\begin{array}{c}\text { Số lượng } \\
\text { (n) }\end{array}$ & $\begin{array}{c}\text { Tỷ lệ } \\
\text { (\%) }\end{array}$ \\
\hline$<20$ tuối & 5 & 8,06 \\
\hline $21-30$ tuối & 14 & 22,58 \\
\hline $31-40$ tuối & 22 & 35,49 \\
\hline $41-50$ tuối & 11 & 17,74 \\
\hline $51-60$ tuối & 8 & 12,9 \\
\hline$>60$ tuối & 2 & 3,23 \\
\hline Trung bình & $36,85 \pm 11,35$ \\
\hline
\end{tabular}

Bảng 3.1 cho thấy nhóm bệnh nhân từ 21-50 tuổi chiếm tỷ lệ cao nhất: 75,81\% và nhóm bệnh nhân có tỷ lệ thấp nhất là nhóm trên 65 tuổi: $3,23 \%$. Tuổi trung bình của nhóm bệnh nhân nghiên cứu là $36,85 \pm 11,35$. Nghiên cứu khảo sát sức khỏe Tâm thần ở Úc trên 10641 người của
Gonçalves D.C. (2011) cho kết quả tỉ lệ mắc rối loạn lo âu lan tỏa: 25-55 tuổi chiếm 36,15\%. Cho dù thực hiện nghiên cứu trên cộng đồng khác nhau nhưng đều phản ánh tỉ lệ gặp rối loan lo âu lan tỏa hay gặp ở nhóm tuổi 20-50 tuổi, đây là nhóm tuổi có nhiều thay đổi trong công việc, gia đình, kinh tế và là lứa tuổi cống hiến nhiều nhất cho xã hội [2].

Bảng 3.2. Đặc điêm về giới tính của bệnh nhân nghiên cứu

\begin{tabular}{|c|c|c|}
\hline $\begin{array}{c}\text { Chỉ số thống kê } \\
\text { Giới tính }\end{array}$ & $\begin{array}{c}\text { Số lượng } \\
\text { (n) }\end{array}$ & $\begin{array}{c}\text { Tỷ lệ } \\
\text { (\%) }\end{array}$ \\
\hline Nam & 21 & 33,87 \\
\hline$N \tilde{u}^{\prime}$ & 41 & 66,13 \\
\hline
\end{tabular}

Bảng 3.2. cho thấy rối loạn lo âu lan tỏa phố biến ở nữ giới với $66,13 \%$ cao hơn nam giới với $33,87 \%$. Tî lệ nữ giới gấp tỉ lệ nam giới xấp xî̀ 2:1 lần. Tỷ lệ rối loạn lo âu lan tỏa gặp nhiều ở nữ bởi giới nữ trải qua các giai đoạn làm thay đổi đổi cuộc sống của giới nữ như giai đoạn sinh đẻ, tiền mãn kinh và mãn kinh. Các giai đoạn này làm thay đổi nồng độ oxytocin, serotonin và prolactin là nguyên nhân làm tăng tỷ lệ rối loạn lo âu lan tỏa.

Bảng 3.3. Số lần phát bệnh ở bệnh nhân trầm cám

\begin{tabular}{|c|c|c|}
\hline Số lân tái phát & $\begin{array}{c}\text { Cố lượng } \\
\text { (n) }\end{array}$ & $\begin{array}{c}\text { Tỷ lế } \\
\text { (\%) }\end{array}$ \\
\hline Một lần & 11 & 17,74 \\
\hline Hai lần & 16 & 25,81 \\
\hline Ba lần & 21 & 33,87 \\
\hline Bốn lần & 7 & 11,29 \\
\hline Năm lần & 5 & 8,06 \\
\hline > Sáu lần & 2 & 3,23 \\
\hline
\end{tabular}

Bảng 3.3 cho thấy, hầu hết là các bệnh nhân rối loạn lo âu lan tỏa tái phát lần hai và lần ba chiếm tỷ lệ cao $59,68 \%$ và điều trị lần đâu tiên với tỉ lệ $17,74 \%$. Kết quả nghiên cứu của chúng tôi cũng phù hợp với kết quả nghiên cứu của Kroenke K. (2007) khi cho rằng bệnh nhân rối loạn lo âu lan tỏa tái phát lần hai và lần ba chiếm tỷ lệ cao nhất với tỷ lệ 46,23\% [3].

Bảng 3.4. Phân bố chuyên khoa đã khám ở bệnh nhân nghiên cứu

\begin{tabular}{|c|c|c|}
\hline Chuyên khoa khám & $\begin{array}{c}\text { Cố lượng } \\
\text { (n) }\end{array}$ & $\begin{array}{c}\text { Tỷ lệ } \\
\text { (\%) }\end{array}$ \\
\hline Đa khoa & 7 & 11,29 \\
\hline Đông y & 4 & 6,45 \\
\hline Hố hấp & 2 & 3,23 \\
\hline Nội tiết & 4 & 6,45 \\
\hline Tiều hóa & 2 & 3,23 \\
\hline Tim mạch & 16 & 25,81 \\
\hline Tâm thần & 27 & 43,54 \\
\hline \multicolumn{2}{|c|}{}
\end{tabular}


Kết quả bảng 3.4 cho thấy tới 56,46\% bệnh nhân khám không đúng chuyên nhành và chỉ có 43,54\% các bệnh nhân đến đúng chuyên khoa tâm thần. Trong các chuyên nghành không phù hợp thì khám tim mạch là nhiều nhất với $25,81 \%$; chuyên khoa đa khoa với $11,29 \%$. Điều này có thể được giải thích bởi rối loạn lo âu lan tỏa không những đặc trưng bởi tình trạng lo âu quá mức mà còn kèm theo nhiều triệu chứng cơ thể. Theo Montgomery O. (2012), chỉ có khoảng 13,3\% bệnh nhân đi khám vì triệu chứng lo âu còn lại hẩu hết bệnh nhân đi khám vì các triệu chứng cơ thể khác nhau. Thêm vào đó sự nhận thức không đầy đủ về các bệnh lý Tâm thần cũng làm cho bệnh nhân không lựa chọn chuyên khoa khám bệnh đầu tiên là chuyên khoa Tâm thần [4].

Bảng 3.5. Đặc điểm các triệu chứng khởi phát của bệh nhân

\begin{tabular}{|c|c|c|}
\hline TC khởi phát & $\begin{array}{c}\text { Cố lượng } \\
\text { (n) }\end{array}$ & $\begin{array}{c}\text { Tỷ lệ } \\
\text { (\%) }\end{array}$ \\
\hline Hồi hộp & 59 & 95,16 \\
\hline Bồn chồn & 53 & 85,48 \\
\hline Ngủ kém & 43 & 69,35 \\
\hline Căng thằng & 27 & 43,54 \\
\hline
\end{tabular}

Kết quả bảng 3.5 cho thấy các bệnh nhân thường có nhiều triệu chứng khởi phát. Các triệu chứng khởi phát thường gặp của bệnh nhẩn nghiên cứu là triệu chứng hồi hộp $(95,16 \%)$ và bồn chồn $(85,48 \%)$. Quá trình tăng hoạt động thần kinh thực vật, đặc biệt nồng độ serotonin giảm là nguyên nhân chính làm tăng hồi hộp và bồn chồn. Tiếp theo là các triệu chứng khởi phát khác thường gặp là ngủ kém $(69,35 \%)$ và triệu chứng căng thẳng $(43,54 \%)$. Sự phân bố các triệu chứng khởi phát đa dạng và không đồng đều cũng chính là kết quả nghiên cứu Trần Nguyễn Ngọc (2018) khi bệnh nhân đến khám với các triệu chứng cơ thể với triệu chứng cơ năng như hồi hộp và mất ngủ [5].

Bảng 3.6. Thời gian mang bệnh của bệnh nhân nghiên cứu

\begin{tabular}{|c|c|c|}
\hline Thời gian & $\begin{array}{c}\text { Số lượng } \\
(\mathbf{n})\end{array}$ & $\begin{array}{c}\text { Tỷ lế } \\
(\mathbf{\%})\end{array}$ \\
\hline$<12$ tháng & 37 & 59,67 \\
\hline $12-24$ tháng & 16 & 25,81 \\
\hline$>24$ tháng & 9 & 14,52 \\
\hline Trung bình & \multicolumn{2}{|c|}{$15,38 \pm 9,85$} \\
\hline
\end{tabular}

Bảng 3.6 cho thấy thời điểm mang bệnh của bệnh nhân nghiên cứu dưới 12 tháng chiếm tỷ lệ cao nhất $(59,67 \%)$, tiếp đó là từ 12 tháng đến 24 tháng $(25,81 \%)$ và trên 24 tháng chiếm tỉ lệ thấp nhất $(14,52 \%)$. Thời gian mang bệnh ngắn nhất là 3 tháng và thời gian mang bệnh lâu nhất là 51 tháng. Thời gian mang bệnh dàn trải ở các tháng khác nhau do đặc điểm lâm sàng của rối loạn lo âu lan tỏa và sức khỏe tâm thần chưa được quan tâm đúng mức. Kết quả này tương tự nghiên cứu của Trần Nguyễn Ngọc (2018) khi thấy đa số bệnh nhân có thời gian mang bệnh là $20,04 \pm 20,84$ tháng [5].

\subsection{2. Đặc điểm lâm sàng rối loạn lo âu} lan tỏa

Bảng 3.7. Chủ đề lo âu thường gặp ở bệnh nhân nghiên cứu

\begin{tabular}{|c|c|c|}
\hline Chủ đề lo ầ số thống kê & $\begin{array}{c}\text { Số lượng } \\
\text { (n) }\end{array}$ & $\begin{array}{c}\text { Tỷ lệe } \\
\text { (\%) }\end{array}$ \\
\hline Bệnh tật & 51 & 82,26 \\
\hline Công việ̂ & 46 & 74,19 \\
\hline Gia đình & 41 & 66,13 \\
\hline Kinh tế & 34 & 54,84 \\
\hline Xã hội & 19 & 30,64 \\
\hline
\end{tabular}

Các chủ đề lo âu của bệnh nhân là các chủ đề thường gặp trong cuộc sống hàng ngày, các chủ đề nhỏ nhăăt, vụn vặt và luôn thay đổi theo hàng ngày và thay đổi theo từng tình huống. Trong nghiên cứu của chúng tôi, phần lớn các lo âu là chủ đề bệnh tật $(82,26 \%)$, công việc $(74,19 \%)$ và gia đình $(66,13 \%)$. Ít gặp nhất là chủ đề về xã hội (30,64\%). Tương tự với nghiên cứu của chúng tôi, một số nghiên cứu đã kiểm tra các chủ đề lo lắng ở bệnh nhân rối loạn lo âu lan tỏa và cho biết các chủ đề lo âu thường gặp là gia đình, tài chính, công việc, bệnh tật và chủ đề nhỏ [6].

Bảng 3.8. Số chủ đề lo âu lan tỏa ở bệnh nhân nghiên cứu

\begin{tabular}{|c|c|c|}
\hline Số chủ để lổ lo âu & $\begin{array}{c}\text { Số lượng } \\
\text { (n) }\end{array}$ & $\begin{array}{c}\text { Tỷ lệ } \\
\text { (\%) }\end{array}$ \\
\hline Một chủ đề & 22 & 35,48 \\
\hline Hai chủ đề & 45 & 72,58 \\
\hline Ba chủ đề & 11 & 17,74 \\
\hline Bốn chủ đề & 5 & 8,06 \\
\hline
\end{tabular}

Kết quả nghiên cứu bảng 3.8 chỉ ra rằng có sự giao thoa và thay đổi chủ đề lo âu. Bệnh nhân rối loạn lo âu lan tỏa thường lo lắng về nhiều chủ đề, ít khi khư trú vào một chủ đề nhất định. Thường gặp nhất là bệnh nhân có hai chủ đề lo âu $(72,58 \%)$, tiếp đó đến một chủ đề lo âu và ba chủ đề lo âu (35,48\% và $17,74 \%)$. Bệnh nhân có bốn chủ đề lo âu ít gặp nhất chiếm tỉ lệ $8,06 \%$. Chủ đề loa âu từ hai chủ đề trở lên chiêm tỷ lệ lớn $(98,38 \%)$ chính số chủ đề nhiều dẫn đến việc kiếm soát triệu chứng lâm sàng khó khăn cả bằng liệu pháp hóa dược cũng như liệu pháp tâm lý cho bác sĩ điều trị. Kết quả này tương đồng nghiên cứu của Crocq M.A. (2017) khi nhận định rằng số chủ đề của rối loạn lo âu 
VIETNAM MEDICAL JOURNAL N¹ - APRIL - 2021

lan tỏa chủ yếu có từ hai chủ đề trở lên [6].

Bảng 3.9. Thời gian tồn tại lo âu lan tỏa của bêenh nhân nghiên cứu

\begin{tabular}{|c|c|c|}
\hline $\begin{array}{c}\text { Chỉ số thống kê } \\
\text { Thời gian tốn tại }\end{array}$ & $\begin{array}{c}\text { Số lượng } \\
\text { (n) }\end{array}$ & $\begin{array}{c}\text { Tỷ lệ } \\
\text { (\%) }\end{array}$ \\
\hline$>10$ phút & 14 & 22,58 \\
\hline $10-20$ phút & 25 & 40,32 \\
\hline $21-30$ & 17 & 27,42 \\
\hline$>30$ phút & 6 & 9,68 \\
\hline Trung bình & \multicolumn{2}{|c|}{$19,35 \pm 11,26$} \\
\hline
\end{tabular}

Nghiên cứu của chúng tôi thấy thời gian tồn tai của triêu chứng lo âu trung bình 19,35 11,26 phút. Trong đó thời gian tồn tại của triệu chứng lo âu từ 10-20 phút chiếm tỷ lệ cao nhất với 25 bênh nhân chiếm $40,32 \%$ và thời gian tồn tai của triệu chứng lo âu trên 30 phút với 6 bệnh nhân chiếm 9,68\%. Chính thời gian tồn tại của triệu chứng lo âu làm ảnh hưởng nặng nề về chất lượng cuộc sống và công việc của bệnh nhân. Tương tự nghiên cứu Gordon B.R. (2017) khi khẳng định thời gian tồn tại của lo âu lan tỏa trên 10 phút chiếm tỷ lệ cao nhất [7].

Bảng 3.10. Đăc điểm triều chúng cơ thể của bệnh nhân nghiên cứu

\begin{tabular}{|c|c|c|c|}
\hline Chỉ số thống & ố lượng & Tỷ lệ & $\mathbf{p}$ \\
\hline Triệu chứng & (n) & $\frac{(\%)}{8226}$ & \\
\hline $\begin{array}{c}\text { Hồi hộp } \\
\text { Vã mồ hôi }\end{array}$ & $\frac{51}{43}$ & $\frac{82,<0}{69,35}$ & \\
\hline Khó thơ & 34 & 54,84 & \\
\hline Đau ngực & 25 & 40,32 & \\
\hline $\begin{array}{c}\text { Cơn nóng bừng, } \\
\text { buốt lanh }\end{array}$ & 21 & 33,87 & \\
\hline Buôn nôn, nôn & 16 & 25,81 & \\
\hline
\end{tabular}

Bảng 3.10 cho thấy, tần suất xuất hiện triệu chứng hồi hộp và vã mồ hôi cao hơn triệu chứng khó thở và đau ngực $(82,26 \%$ và $69,35 \%$ so với $54,84 \%$ và $40,32 \%)$. Điều này thể hiện rõ biểu hiện của sự rối loạn các chất dẫn truyền thần kinh và rối loạn hê thần kinh thực vật. Hơn nữa rối loạn thần kinh thực vật gây $c 0$, giãn mạch máu bất thường làm xuất hiện triệu chứng khó thở và đau ngức. Nhóm triêu chứng cơ thể chính là nguyên nhẩn để bênh nhân khám bênh ở khoa Tim mạch và khoa Thần kinh trước khi đến chuyên khoa Tâm thần. Tác giả Trần Nguyễn Ngọc (2018) cũng cho kết quả tương tự với trên $60 \%$ bênh nhân rối loạn lo âu lan tỏa có triệu chứng khó thở và đau ngực [5].

Bảng 3.11. Đặc điểm triệu chứng tâm thần của bênh nhân nghiên cứu

\begin{tabular}{|c|c|c|c|c|}
\hline \multicolumn{2}{|c|}{$\begin{array}{l}\text { Chi số thống kê } \\
\text { Triệu chứng }\end{array}$} & $\begin{array}{c}\text { Số } \\
\text { lượng(n) }\end{array}$ & $\begin{array}{l}\text { Tỷ lệ } \\
(\%)\end{array}$ & \\
\hline Triệu & Chóng mặt & 52 & 83,87 & \\
\hline chứng & Sợ mất & 35 & 56,45 & \\
\hline
\end{tabular}

\begin{tabular}{|c|c|c|c|}
\hline tâm & kiềm chế & & \\
\cline { 2 - 4 } thần & Sợ bị chết & 27 & 43,55 \\
\hline \multirow{4}{*}{$\begin{array}{c}\text { Triêu } \\
\text { chứng } \\
\text { căng } \\
\text { thẳng }\end{array}$} & $\begin{array}{c}\text { Khó tập } \\
\text { trung }\end{array}$ & 51 & 82,26 \\
\cline { 2 - 4 } & $\begin{array}{c}\text { Bồn chồn } \\
\text { tâm thằng }\end{array}$ & 47 & 75,81 \\
\cline { 2 - 4 } & $\begin{array}{c}\text { Cáu kỉnh } \\
\text { dai dẳng }\end{array}$ & 21 & 54,84 \\
\hline
\end{tabular}

Bảng 3.11 cho thấy đa số bệnh nhân có triệu chứng chóng mặt chiếm tỉ lệ $65,2 \%$; triệu chứng này nguyên nhẩn do rối loạn nhịp thở dẫn đến rối loạn nồng độ $\mathrm{CO}_{2}$ và $\mathrm{O}_{2}$ trong máu. Trong đó bệnh nhân nữ thường biểu hiện chóng mặt nhiều hởn bênh nhân nam. Triệu chứng tâm thần còn thể hiện ở sỡ mất kiềm chế và sợ bị chết với tỷ lệ $56,45 \%$ và $43,55 \%$. Ngoài ra triệu chứng khó tập trung $(82,26 \%)$ và triệu chứng bồn chồn $(75,81 \%)$ là 2 biểu hiện hay gặp trong nhóm triêu chứng căng thẳng. Chính hai nhóm triệu chứng tâm thần và triệu chứng căng thẳng làm cho biểu hiện lâm sàng của bệnh nhân đa dạng và trầm trọng hơn [5].

Bảng 3.12. Đăc điểm mức đô lo âu theo HAM-A

\begin{tabular}{|c|c|c|c|}
\hline $\begin{array}{l}\text { Chis số thống kê } \\
\text { Mức độ }\end{array}$ & $\begin{array}{l}\text { Số lượng } \\
\text { (n) }\end{array}$ & \begin{tabular}{|l|} 
Tỷ lế \\
$(\%)$
\end{tabular} & p \\
\hline $\begin{array}{c}\text { Lo âu lan tỏa mức } \\
\text { độ nhe }\end{array}$ & 13 & 20,97 & \\
\hline $\begin{array}{c}\text { Lo âu lan tóa mức } \\
\text { độ vứa }\end{array}$ & 16 & 25,81 & $<0,05$ \\
\hline $\begin{array}{l}\text { Lo âu lan tỏa mức } \\
\text { đô năng }\end{array}$ & 33 & 53,22 & \\
\hline
\end{tabular}

Theo HAM-A, mức độ nặng chiếm tỉ lệ cao $53,22 \%$. Tiếp đến là mức độ vừa với tỉ lệ $25,81 \%$. Ít gặp nhất là mức độ nhẹ với 20,97\%. Kết quả này phản ánh một thực tế hầu bênh nhân rối loạn lo âu lan tỏa đến khám và điều trị khi tình trạng bệnh ở mức độ nặng (do vấn đề kinh tế, cồng việc khiến bệnh nhân không đủ điều kiện). Kết quả này tương tự nghiên cứu của Srivastava S. (2020) khi thấy ở bệnh nhân rối loạn lo âu lan tỏa thì tỷ lê bênh nhẩn rối loan lo âu lan tỏa mức độnặng với thang điểm HAMM-A chiếm tỷ lệ cao nhất [8].

\section{KẾT LUẬN}

Bệnh nhân từ 21-50 tuổi chiếm tỷ lệ cao nhất: $75,81 \%$ và phổ biến ở nữ giới với $66,13 \%$. Hầu hết các bệnh nhân tái phát lần hai chiếm tỷ lệ cao $59,68 \%$ và có tới $56,46 \%$ bệnh nhân khám không đúng chuyên nhành. Các triệu chứng khởi phát thường gặp của bệnh nhân là triệu chứng hồi hộp $(95,16 \%)$ và thời gian mang bệnh là 15,38 $\pm 9,85$ tháng.

Phần lớn chủ đề lo âu về bệnh tật $(82,26 \%)$, 
có hai chủ đề lo âu đồng thời (72,58\%) và thời gian tồn tại của triệu chứng trung bình 19,35 \pm 11,26 phút. Tân suất xuất hiện triệu chứng hôi hộp $(82,26 \%)$; chóng mặt $(65,2 \%)$. Ngoài ra triệu chứng tâm thân thường gặp nhất là triệu chứng chóng mặt $(83,87 \%)$ và điểm HAM-A cho nặng chiếm tỉ lệ cao nhất với 53,22\%.

\section{TÀI LIÊU THAM KHẢO}

1. Strawn J.R., Geracioti L., Rajdev N. et al. (2018), "Pharmacotherapy for generalized anxiety disorder in adults and pediatric patients: An evidence-based treatment review", Expert Opin Pharmacother; 19(10): 1057-1070.

2. Gonçalves D.C., Pachana N.A. and Byrne G.J. (2011), Prevalence and correlates of generalized anxiety disorder among older adults in the Australian National Survey of Mental Health and Well-Being", Psychological Medicine; 32, 649-659.

3. Kroenke K., Spitzer R.L., Williams J.B. et al. (2007), "Anxiety disorders in primary care: prevalence, impairment, comorbidity, and detection",
Annals of Internal Medicine; 146, 317-325.

4. Montgomery 0 ., Follen $M$. and UrdanetaHartmann S. (2012), "The 2010 annual sex and gender research forum at drexel university and drexel university college of medicine: an institute for women's health and leadership initiative. Introduction", Gend Med; 9(1 Suppl): 1-6.

5. Trân Nguyễn Ngọc (2018), "Đánh giá hiệu quả điều trị rối loan lo âu lan tỏa bằng liệu pháp thư giãn-luyện tập", Luận án tiến sỹ; Đại học y Hà Nội.

6. Crocq M.A. (2017), "The history of generalized anxiety disorder as a diagnostic category", Dialogues Clin Neurosci; 19(2): 107-116.

7. Gordon B.R., McDowell C.P., Lyons M. et al. (2017), "The effects of resistance exercise training on anxiety: A meta-analysis and metaregression analysis of randomized controlled trials", Sports Med; 47(12): 2521-2532.

8. Srivastava S., Menon V., Kayal S. et al. (2020), "Level of anxiety and depression and its clinical and sociodemographic determinants among the parents of children with cancer undergoing chemotherapy", J Neurosci Rural Pract; 11(4): 530-537.

\title{
ĐÁNH GIÁ HIÊUU QUẢ ĐIỀU TRI DỰ PHÒNG SINH NON Ở THAI PHỤ Có Độ DÀI CỔ TỬ CUNG NGẮN BẲNG PROGESTERONE ĐƯờNG ÂM ĐẠO
}

\author{
Vũ Bá Quyết*, Nguyễn Xuân Họi*, Phan Thị Thu Nga*, \\ Nguyễn Thị Huyền Linh*, Hoàng Phương Ly*

\section{SUMMARY \\ EVALUATION OF THE EFFICACY OF PROPHYLACTIC TREATMENT OF PRETERM BIRTH IN PREGNANT WOMEN WITH A SHORT CERVIX WITH VAGINAL PROGESTERONE}

TÓM TẮT

Mục tiêu: Đánh giá hiệu quả điều trị dự phòng sinh non ở thai phụ có cổ tử cung (CTC) ngắn bằng Progesterone đường âm đạo.Đối tượng và phương pháp nghiên cứu: Nghiên cứu can thiệp không đối chứng. 65 thai phu tuần thai từ 19 tuần -23 tuần 6 ngày đến khám thai tại Bệnh viện Phụ Sản Trung ương được siêu âm đường âm đạo xác đinh có đô dài cổ tử cung $\leq 25 \mathrm{~mm}$ và phù hợp với tiểu chuẩn lựa chọn và tiêu chuẩn loại trừ. Các thai phụ được điều trị dư phòng bằng đăt 1 viên Utrogestan âm đao vào buổi tối liên tuc từ khi thu nhân đến khi thai hết 36 tuần. Kết quả nghiên cứu: ț̉ lê đẻ non $<28$ tuần chiếm $6,1 \%$; dưới 34 tuần $12,3 \%$, dưới 35 tuần $16,9 \%$ và dưới 37 tuần $33,8 \%$. Số thai phu không đẻ non ( $\geq 37$ tuần) là: $66,2 \%$. Tình trạng trẻ sau sinh: $12,3 \%$ trẻ tử vong, $87,7 \%$ trẻ sống khỏe manh; $81,5 \%$ trẻ có cân nặng $\geq 2.500$ gram và $18,5 \%$ trẻ có cân nặng < 2.500 gram. Kết luận: Điều trị dự phòng progesterone cho phụ nữ mang thai có CTC ngắn có hiệu quả giảm tỷ lệ sinh non.

Tư khóa: đẻ non, độ dài cổ tử cung, Progesterone.

*Bệnh viện Phụ Sản Trung ương Chịu trách nhiệm chính: Vũ Bá Quyết Email: Quyetvb2000@yahoo.com Ngày nhân bài: 25.01.2021

Ngày phản biên khoa học: 22.3.2021 Ngày duyệt bài: 30.3.2021
Objective: To evaluate the efficacy of prophylactic treatment of preterm birth in pregnant women with a short cervix with vaginal progesterone. Subjects and research methods: A non-controlled intervention study involved 65 pregnanciesat $19-23$ weeks and 6 days gestation at the National Hospital Obstetrics and Gynecology are determined by vaginal ultrasound to have a length of the cervix $\leq 25 \mathrm{~mm}$ and met the inclusive and exclusive criteria. Pregnant women received prophylactic treatment with 1 tablet vaginal Utrogestan in the evening continuously from enrollment to the end of the 36-week pregnancy. Research results: the rate of preterm birth $<28$ weeks accounted for $6.1 \%$; less than 34 weeks $12.3 \%$, less than 35 weeks $16.9 \%$ and under 37 weeks $33.8 \%$. The number of pregnant women who did not give birth prematurely ( $\geq 37$ weeks) was: $66.2 \%$. Postpartum status: $12.3 \%$ of children die, $87.7 \%$ of children live healthy; $81.5 \%$ of children were $\geq 2,500$ grams and $18.5 \%$ were $<2,500$ grams. Conclusion: Progesterone prophylaxis for pregnant women with a short cervix is effective in reducing the rate of preterm birth.

Keywords: preterm birth, cervical length, Progesterone. 